\title{
Jean Braybrook, Les larmes de Pierre de Ronsard
}

\section{Michele Mastroianni}

\section{(2) OpenEdition}

\section{Journals}

\section{Edizione digitale}

URL: http://journals.openedition.org/studifrancesi/401

DOI: 10.4000/studifrancesi.401

ISSN: 2427-5856

\section{Editore}

Rosenberg \& Sellier

\section{Edizione cartacea}

Data di pubblicazione: 1 aprile 2015

Paginazione: 136

ISSN: 0039-2944

\section{Notizia bibliografica digitale}

Michele Mastroianni, « Jean Braybrook, Les larmes de Pierre de Ronsard », Studi Francesi [Online], 175

(LIX | I) | 2015, online dal 01 avril 2015, consultato il 18 septembre 2020. URL : http://

journals.openedition.org/studifrancesi/401 ; DOI : https://doi.org/10.4000/studifrancesi.401

\section{Questo documento è stato generato automaticamente il 18 settembre 2020.}

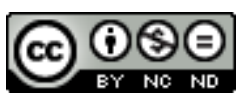

Studi Francesi è distribuita con Licenza Creative Commons Attribuzione - Non commerciale - Non opere derivate 4.0 Internazionale. 


\title{
Jean Braybrook, Les larmes de Pierre de Ronsard
}

\author{
Michele Mastroianni
}

\section{NOTIZIA}

JEAN BRAYBROOK, Les larmes de Pierre de Ronsard, «Revue des Amis de Ronsard», XXVI, 2013, pp. 35-46.

1 L'A. analizza il trattamento del tema delle lacrime nella Franciade, leggendo il poema ronsardiano in parallelo con l'Eneide. Le lacrime di Francus, come quelle di Enea, sono segno di rimpianto: mentre però Virgilio collega il pianto individuale alla sofferenza universale («sunt lacrimae rerum»), Ronsard disegna un Francus ripiegato in se stesso e sulle sue pene interiori («se laissant en larmes consommer»), le cui lacrime evidenziano sempre una profonda stanchezza. Anche quando le lacrime, in una prospettiva funeraria, sono manifestazione di lutto, la ritualità del canto VI dell'Eneide cede al larmoyer sans confort della Franciade. Diversamente fedele alla classicità, Ronsard riprende il tema delle lacrime nella poesia amorosa di deuil (l'A. legge brevemente in questa prospettiva il sonetto «Comme on voit sur la branche au mois de May la rose»). 